\title{
Extent of Insecticide Residue Load in Vegetables Grown under Conventional Farming in Bangladesh
}

\author{
M. S. Ahmed ${ }^{1}$, Afroza Begum ${ }^{1}$, M. A. Rahman ${ }^{1}$, M. W. Akon ${ }^{1}$ and M. A. Z. Chowdhury ${ }^{2}$ \\ ${ }^{1}$ Entomology Division, Bangladesh Agricultural Research Institute, Gazipur-1701, Bangladesh \\ ${ }^{2}$ Institute of Food and Radiation Biology, AERE, Savar, Dhaka-1349, Bangladesh \\ *Corresponding author and Email: sultan_palbari@yahoo.com
}

Received: 02 November 2016

Accepted: 12 December 2016

\begin{abstract}
The study was carried out to detect and quantify the left over residues of eight commonly used insecticides (fenvalerate, diazinon, quinalphos, fenitrothion, acephate, chlorpyriphos, cypermethrin and malathion) in brinjal, yard long bean, bitter gourd, snake gourd, pointed gourd, okra, tomato, hyacinth bean and cabbage samples collected from local market of eight different regions like Jessore, Comilla, Narsingdi, Tangail, Rangpur, Jamalpur, Gazipur and Dhaka during 2011-2012 seasons. Among the170 analyzed samples, $21.78 \%$ were contaminated with four insecticides (chlorpyriphos, quinalphos, acephate and cypermethrin) either single or multiple product residue, in which $18.26 \%$ samples had residue above MRL. The vegetables of Norsingdi, Jessore and Comilla had more insecticide residue in comparison to other locations. Most of the samples contain chlorpyriphos (13.53\%) and quinalphos (8.4\%) residue. Acephate, chlorpyriphos and quinaphos were also found as multiple product residues expressing $2.35 \%$ of the total samples which were above MRL and $19.41 \%$ sample contained single product residue with chlorpyriphos, quinaphos and cypermethrin where $15.88 \%$ were of above MRL. Cypermethrin residue was detected only in two samples (brinjal and yard long bean) which were below MRL.
\end{abstract}

Keywords: Insecticide, organophosphorus, residue, vegetables, MRL.

\section{Introduction}

Bangladesh has an irresistible agricultural economy. Production of agricultural produces is being increased every year to meet the growing demand of the people. Diversification of vegetable crops and increasing commercialization can support the development of the agriculture sector in several ways. But, in case of vegetables, data show the output growth in Bangladesh mainly through area expansion, without much improvement in yield. One potential drawback associated with a shift toward more intensive vegetable production is the common reliance of most vegetable producers on heavy application of pesticide (Hossain et al., 2000). Among the vegetables grown in Bangladesh, brinjal, tomato, cabbage, bitter gourd, snake gourd, pointed gourd, okra, hyacinth bean and yard long bean are nutritious, valuable and very popular to consumers. It has been reported that in brinjal, bitter gourd and beans, the attack of insect pests are severe and farmers sprayed pesticides quite frequently even every day (Anonymous, 2001; Ahmed et al., 2005). Extensive deliberate use of pesticides has 
resulted in contamination of vital supplies, air, water and food. The risk to humans may be short term as well as long term depending on the persistence of the pesticide and the exposure period. Pesticide residue in food makes deleterious effect on human health such as headaches and nausea to chronic impacts like cancer, reproductive harm and endocrine disruption (Berrada et al., 2010). Now pesticide residue in food has become a consumer's safety issue and the consumers have the right to know how much pesticide get incorporated in the food they eat. However, very little references are available on the presence of pesticides in vegetables in Bangladesh (Khatoon et al., 2004). Under such circumstances, the present study was undertaken to detect and quantify the amount of leftover residue of pesticide in different vegetable samples collected from local market of different regions of Bangladesh.

\section{Materials and Methods}

One hundred seventy vegetable samples viz., brinjal, cabbage, hyacinth bean, yard long bean, bitter gourd, snake gourd, pointed gourd, okra and tomato were collected from local market of eight different regions namely Comilla, Gazipur, Jessore, Norsingdi, Tangail, Dhaka, Jamalpur and Rangpur (Table 1). The weight of the sample of each vegetable was $1 \mathrm{~kg}$. Samples were collected according to regulation made in the "Guidelines for the control of pesticide residues in foods" (Anonymous, 1996), which incorporate the EU directive (Anonymous, 1979) and Codex recommendations (Anonymous, 1993) regarding sampling. Collected samples were kept in "Chilled box" and carried to the laboratory within the quickest time and stored in refrigerator $\left(-20^{\circ} \mathrm{C}\right)$ until analysis.

The standard for diazinon, malathion, quinalphos, fenitrothion, chlorpyriphos, acephate, fenvalerate and cypermethrin were obtained from Sigma-Aldrich Laborchemikalien, Seelze, Germany via Bangladesh Scientific Pvt. 1td. Dhaka, Bangladesh. Standards of all the insecticides contained $>99.6 \%$ purity.
Chromatograms obtained from standard were used to compare residue of the vegetable samples.

\subsection{Extraction, separation and clean up of vegetable samples}

The collected vegetable samples (250g) were chopped by knife on white board and mixed well. A sub sample of $20 \mathrm{~g}$ was taken into a wide mouth jar with the help of a spatula then $100 \mathrm{ml}$ of hexane was added to it. Sodium sulphate $\left(\mathrm{Na}_{2} \mathrm{SO}_{4}\right)$ was also added with sample until water was removed from the sample. The mixture was then macerated with high-speed homogenizer (Ultra-turrax, IKA T18 basic, Germany) for 2 minutes. The homogenized material was then poured into $250 \mathrm{ml}$ conical flask and placed into the shaker (Refrigerated Shaker, Rexmed, Sweden) for $12 \mathrm{hrs}$ continuous shaking. After shaking, the slurry was filtered through whatman filter paper no.40 and a buchner funnels with suction. The flask and filter cakes were rinsed with $25 \mathrm{ml}$ of hexane each. The filtrate was then transferred into $250 \mathrm{ml}$ round bottom flask and was dried to around 5-7 $\mathrm{ml}$ by evaporation using a rotary vacuum evaporator (Laborota-4001, Heidolph, Germany) at $35-40^{\circ} \mathrm{C}$. Then, the concentrate filtrate was collected in a centrifuge tube adjusted at $10 \mathrm{ml}$ volume which was then centrifuged at $16500 \mathrm{rpm}$ for 10 minutes with laboratory refrigerated centrifuges (Sigma-3K30, Germany). After centrifuge, supernatant was collected and cleaned up by Super Phase Extraction (SPE) cartridge. Then the final volume was kept in $10 \mathrm{ml}$ volumetric flask. Before injection, this volume was again cleaned up by High Performance Liquid Chromatograph (HPLC) filter (0.2 PTFE) which was ready for injection in Gas Chromatograph.

\subsection{Detection and quantification of insecticide residue in samples}

The concentrated extracts were subjected to analysis by GC-2010 (Shimadzu) with Flame Thirmionic Detector (FTD) for detection of 
organophosphorus (diazinon, quinalphos, acephate, chlorpyriphos, fenitrothion and malathion) insecticide. For detection of pyrethroid (cypermethrin, fenvalerate) each sample extract was again analyzed with Electron Capture Detector (ECD). The capillary column used was AT-1, length $30 \mathrm{~m}$, ID $0.25 \mathrm{~mm}$ and film thickness $0.25 \mu \mathrm{m}$ in case of both detectors. Helium was used as carrier and make up gas in FTD and in case of ECD, it was Nitrogen.

The instrument parameters for detecting organophosphorus and pyrethroid insecticides were as follows:

\section{Organophosphorus Insecticides}

\section{[Injection Port SPL]}

Injection Mode: Split

Temperature: $250^{\circ} \mathrm{C}$

Flow Control Mode: Linear Velocity

Split Ratio: 30.0

[Column Oven]

Initial Temperature: $150^{\circ} \mathrm{C}$

Column Oven Temperature Program:

Total Program Time: $10.00 \mathrm{~min}$

$\begin{array}{ccc}\text { Rate}(\mathrm{C} / \mathrm{min}) & \text {-Temperature } & \left({ }^{0} \mathrm{C}\right) \text {-Hold Time }(\mathrm{min}) \\ - & 150 & 1 \\ 10 & 220 & 2\end{array}$

\section{[Detector Channel 1 FTD]}

Temperature: $280^{\circ} \mathrm{C}$

Stop Time: $10 \mathrm{~min}$

Current: $1.00 \mathrm{pA}$

Makeup Flow: $30 \mathrm{ml} / \mathrm{min}$

$\mathrm{H}_{2}$ Flow: $1.5 \mathrm{~mL} / \mathrm{min}$
Air Flow: $145 \mathrm{ml} / \mathrm{min}$

\author{
Pyrethroid Insecticide \\ [Injection Port SPL] \\ Injection Mode: Split \\ Temperature: $280^{\circ} \mathrm{C}$ \\ Flow Control Mode: Linear Velocity \\ Split Ratio: 10
}

[Column Oven]

Initial Temperature: $160^{\circ} \mathrm{C}$

Column Oven Temperature Program:

Total Program Time: $18.00 \mathrm{~min}$

$\begin{array}{ccc}\text { Rate }(\mathrm{C} / \mathrm{min}) & \text { Temperature } & \left({ }^{0} \mathrm{C}\right) \text {-Hold } \\ - & 160 & 1 \\ 10 & 270 & 6\end{array}$

[Detector Channel 1 ECD]

Temperature $: 300^{\circ} \mathrm{C}$

Stop Time: $18 \mathrm{~min}$

Current: $1.00 \mathrm{pA}$

Makeup Flow: $30 \mathrm{ml} / \mathrm{min}$

Prior to the injection of the sample extract, standard solutions of different concentrations of each pesticide were prepared and injected with selected instrument parameters. The samples were calibrated (retention time, peak area etc.) against three to four pointed calibration curve of standard solution of concerned pesticide. Each peak was characterized by its retention time. Sample results were expressed in mgkg ${ }^{1}$ automatically by the GC software which represented the concentration of the final volume injected. From this value, the actual amount of pesticide residue present in the sample was determined by using the following formula:

\section{Residue in sample $\left(\mathrm{mgkg}^{-1}\right)$ :}

Conc. obtained in injected volume $\left(\mathrm{mgkg}^{-1}\right) \mathrm{X}$ Quantity of final volume (L)

Amount of sample taken $(\mathrm{kg})$ 
Table 1. Basic information about vegetable samples collected from different locations of Bangladesh during 2011-12

\begin{tabular}{|c|c|c|c|c|c|}
\hline Locations & $\begin{array}{l}\text { English } \\
\text { name }\end{array}$ & $\begin{array}{l}\text { Common } \\
\text { name }\end{array}$ & $\begin{array}{l}\text { Edible } \\
\text { part }\end{array}$ & Scientific name & Family \\
\hline \multirow{9}{*}{$\begin{array}{l}\text { Jessore, } \\
\text { Comilla, } \\
\text { Narsingdi, } \\
\text { Tangail, } \\
\text { Rangpur, } \\
\text { Jamalpur, } \\
\text { Gazipur } \\
\text { and Dhaka }\end{array}$} & $\begin{array}{l}\text { Hyacinth } \\
\text { bean }\end{array}$ & Sheem & Pod & Lablab niger & Leguminoseae \\
\hline & $\begin{array}{l}\text { Yard long } \\
\text { bean }\end{array}$ & Borboti & Pod & Vigna sesquipedalis & Fabaceae \\
\hline & Cabbage & Bandhakopi & Head & $\begin{array}{l}\text { Brassica oleracea } \\
\text { var capitata }\end{array}$ & Cruciferae \\
\hline & Tomato & Tomato & Fruit & Lycopersicon esculentum & Solanaceae \\
\hline & Brinjal & Begoon & Fruit & Solanum melongena & Solanaceae \\
\hline & Okra & Dherosh & Fruit & Abelmoschus esculentus & Malvaceae \\
\hline & Bitter gourd & Karala/Ucche & Fruit & Momordica charantia & Cucurbitaceae \\
\hline & Snake gourd & Chichingga & Fruit & Trichosanthes anguina & Cucurbitaceae \\
\hline & $\begin{array}{l}\text { Pointed } \\
\text { gourd }\end{array}$ & Potal & Fruit & Trichosanthes dioica & Cucurbitaceae \\
\hline
\end{tabular}

\section{Results and Discussion}

\subsection{Determination of insecticide residue}

The analytical results of the vegetable samples for the detection and quantification of insecticide residue have been summarized in Table 2. Figure 1 shows the chromatograms of standards of organophosphorus insecticides. Three chromatograms of quinalphos residue obtained from the yard long bean in Norsingdi, Comilla and Jessore regions are shown in Figure 2-4. In this way the results of other samples were also made by in-built GC-2010 software.

A total of 170 samples of nine vegetables viz., brinjal, hyacinth bean, cabbage, bitter gourd, tomato, pointed gourd, snake gourd, okra and yard long bean were collected from local markets of eight districts as Comilla, Jamalpur, Tangail, Gazipur, Dhaka, Rangpur, Jessore and Norsingdi. Analytical results showed that $21.76 \%$ samples were contaminated with four insecticides (chlorpyriphos, quinalphos, acephate and cypermethrin) irrespective of single or multiple product residues, in which $18.26 \%$ samples contained residue above MRL (European Commission, 2016; FAO/WHO,
2016). The detected residue of chlorpyriphos and quinalphos were found more as compared to acephate and cypermethrin. Acephate was detected as multiple products with chlorpyriphos in two samples of snake gourd from Norsingdi which were above MRL but sample of other locations did not have any acephate residue. Another two multiple product (chlorpyriphos, quinalphos) residues were found in brinjal and bitter gourd samples of Jessore location which were also above MRL (Table 2). The presence of multiple product residues indicated that farmers applied more than one pesticide on brinjal and bitter gourd in Jessore and snake gourd in Norsingdi location. Most of the commercial farmers of vegetables especially in Jessore region have been spraying "cocktail" (mixture of 3-5 pesticides) at every or every alternate day (Kabir et al., 1996; Rashid et al., 2003). This whimsical and injudicious use of pesticides on vegetables might cause the multiple residues of pesticides even at or above MRL level.

Cypermethrin residue was found in two samples; one in brinjal from Jessore and another one in yard long bean from Rangpur location and the levels of residue were below MRL which might be due to higher rate of dissipation. 
Table 2. Quantity of residue of different insecticides estimated from vegetable samples of local market collected from different regions of Bangladesh during 2011-2012

\begin{tabular}{|c|c|c|c|c|c|c|}
\hline \multirow[t]{2}{*}{ Vegetables } & \multirow{2}{*}{$\begin{array}{c}\text { Samples } \\
\text { analyzed } \\
\text { (no.) }\end{array}$} & \multicolumn{2}{|c|}{$\begin{array}{c}\text { Contaminated samples } \\
\text { (no.) }\end{array}$} & \multirow[t]{2}{*}{$\begin{array}{l}\text { Detected insecticide and Level of } \\
\text { residue }\left(\mathrm{mgkg}^{-1}\right)\end{array}$} & \multirow[t]{2}{*}{ Frequency } & \multirow[t]{2}{*}{$* \operatorname{MRL}\left(\mathrm{mgkg}^{-1}\right)$} \\
\hline & & Single & Multi & & & \\
\hline \multirow[t]{3}{*}{ Brinjal } & 30 & 3 & 1 & $\begin{array}{ll}\text { Quinalphos: } & 0.326 \\
& 0.069\end{array}$ & 2 & 0.01 \\
\hline & & & & Chlorpyriphos: 0.420 & 2 & 0.05 \\
\hline & & & & Cypermethrin: 0.026 & 1 & 0.03 \\
\hline \multirow[t]{3}{*}{ Hyacinth bean } & 15 & 3 & - & Quinalphos: & 1 & 0.01 \\
\hline & & & & Chlorpyriphos: 0.196 & 2 & 0.05 \\
\hline & & & & 0.407 & & \\
\hline \multirow[t]{4}{*}{ Cabbage } & 6 & 4 & - & Quinalphos: & 2 & 0.01 \\
\hline & & & & 0.098 & & \\
\hline & & & & Chlorpyriphos: 0.406 & 2 & 0.01 \\
\hline & & & & 0.063 & & \\
\hline \multirow[t]{9}{*}{ Bitter gourd } & 20 & 7 & 1 & Quinalphos: & 4 & 0.01 \\
\hline & & & & 0.132 & & \\
\hline & & & & 0.083 & & \\
\hline & & & & 0.065 & & \\
\hline & & & & Chlorpyriphos: 0.200 & 5 & 0.05 \\
\hline & & & & 0.230 & & \\
\hline & & & & 0.441 & & \\
\hline & & & & 0.396 & & \\
\hline & & & & 0.094 & & \\
\hline \multirow[t]{3}{*}{ Tomato } & 30 & 3 & - & Chlorpyriphos: 0.138 & 3 & 0.01 \\
\hline & & & & 0.443 & & \\
\hline & & & & 0.397 & & \\
\hline \multirow[t]{2}{*}{ Pointed gourd } & 10 & 2 & - & Chlorpyriphos: 0.302 & 2 & 0.05 \\
\hline & & & & 0.267 & & \\
\hline
\end{tabular}




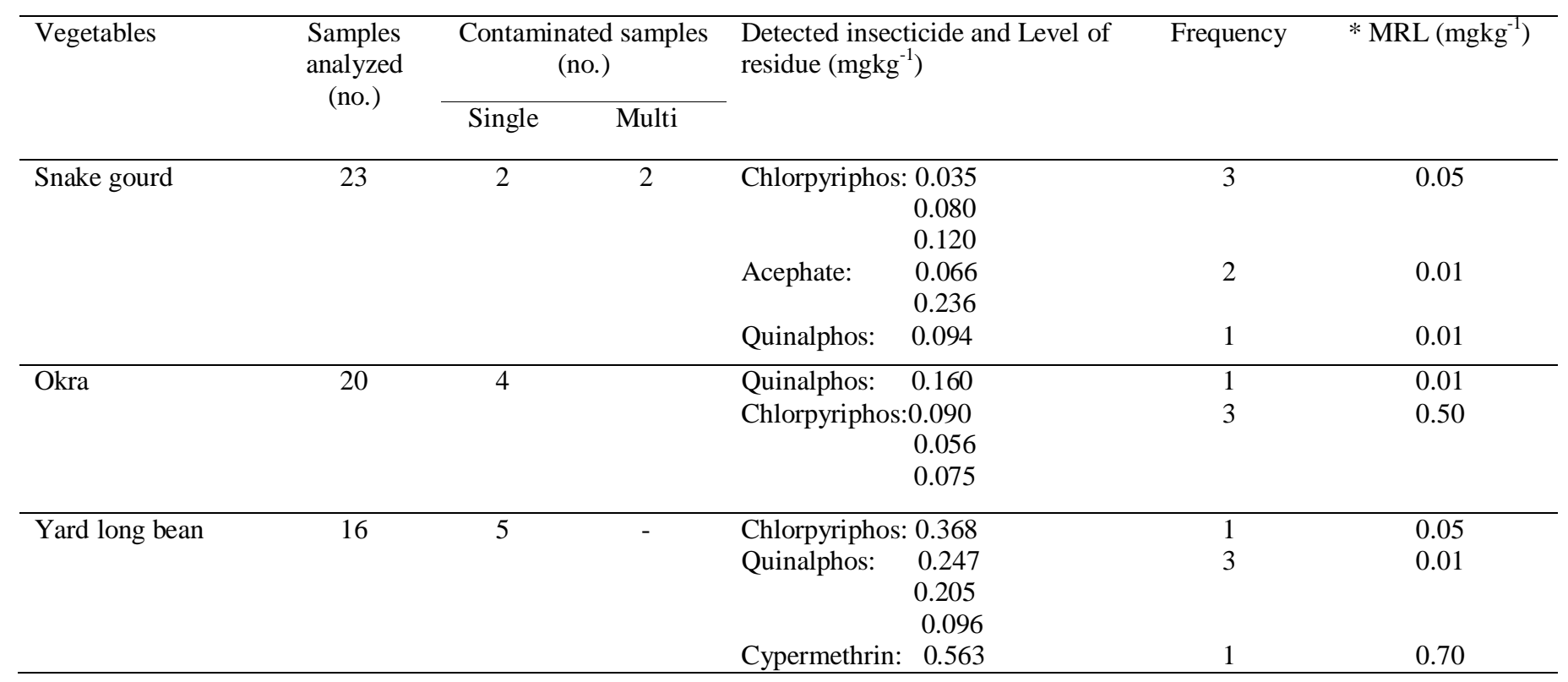




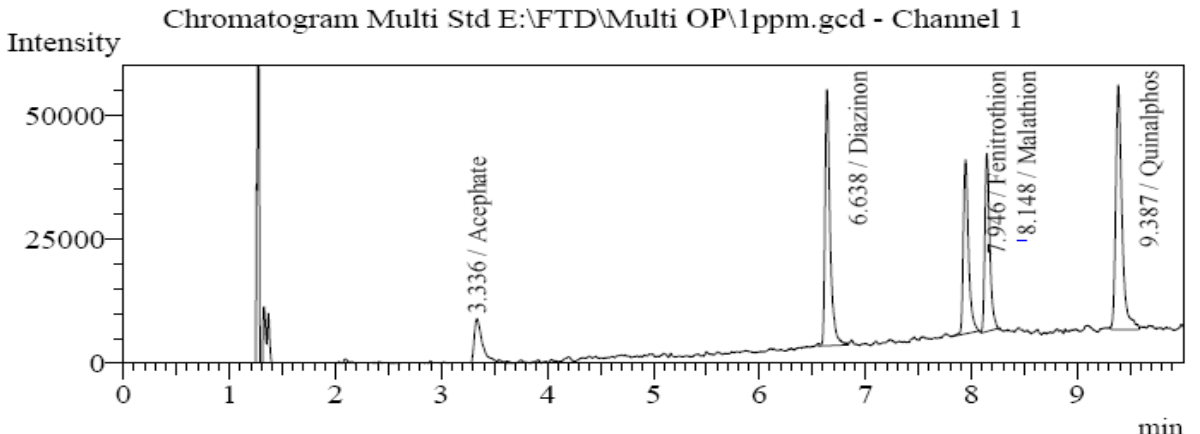

Figure 1. Chromatograms of standards of organophosphorus insecticides run by GC-FTD

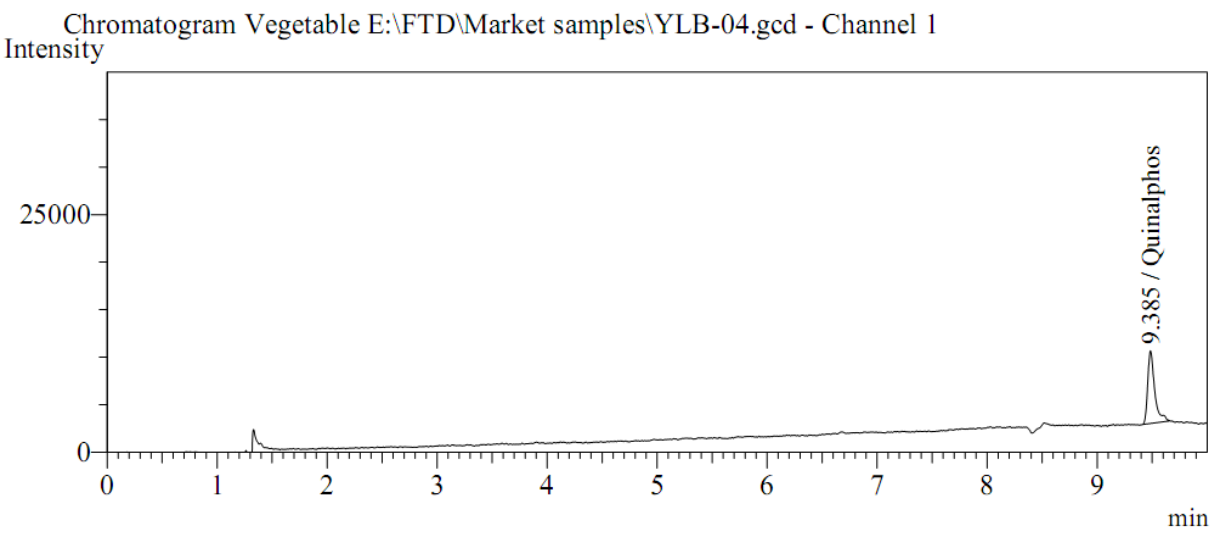

Figure 2. Chromatograms of quinalphos obtained from the extract of yard long bean (YLB04) collected form Jessore region

Chromatogram Vegetable E: $\mid F T D \backslash$ Market samples $\backslash$ YLB-07.ged - Channel 1 Intensity

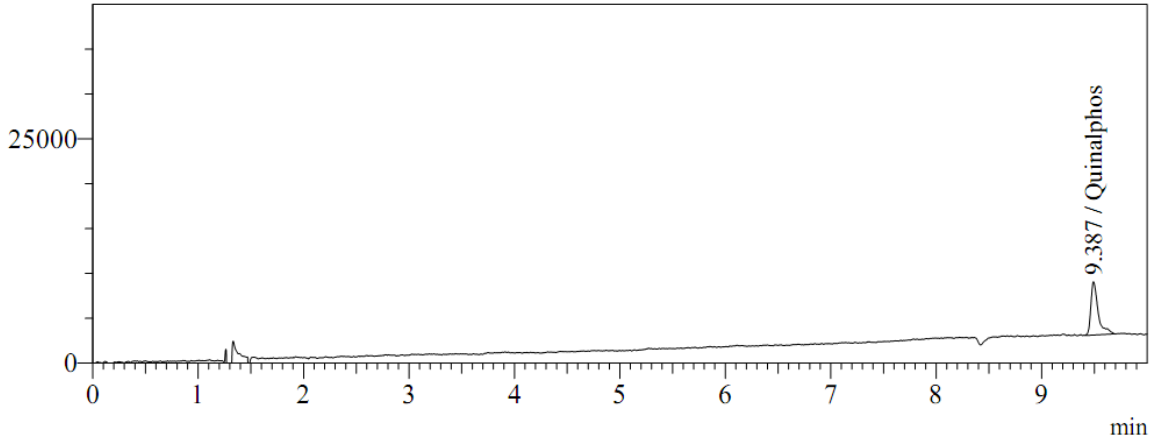

Figure 3. Chromatograms of quinalphos obtained from the extract of yard long bean (YLB07) collected form Norsingdi 


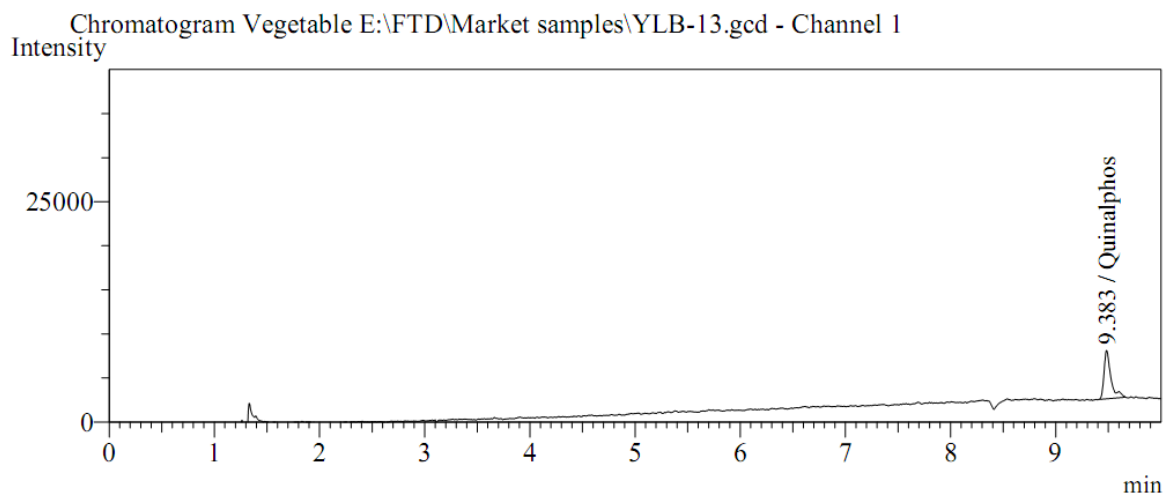

Figure 4. Chromatograms of quinalphos obtained from the extract of yard long bean (YLB-13) collected form Comilla

There were 33 contaminated samples of single product in which 19 samples were of chlorpyriphos (frequency 23), 12 samples were of quinalphos (frequency 14) and two samples of cypermethrin (frequency 2). Fifteen samples contained 0.063 to $0.445 \mathrm{mgkg}^{-1}$ chlorpyriphos residue as a single product which were above MRL and other four samples contained 0.035 to $0.090 \mathrm{mg} / \mathrm{kg}^{-1}$ residue in okra and snake gourd in Gazipur, Tangail, Dhaka and Mymensingh which were below MRL. One sample of tomato in Jessore and two samples of each pointed gourd and tomato in Norsingdi showed chlorpyriphos residues $\left(0.138-0.443 \mathrm{mg} / \mathrm{kg}^{-1}\right)$ which were above MRL (Table 2).

Twelve samples showed quinalphos residue as a single product in brinjal, hyacinth bean, cabbage, bitter gourd, snake gourd, okra and yard long bean in Norshindi, Comilla and Jessore region. All the detected residue levels of quinalphos were above MRL. Fenitrothion, fenvalerate, diazinon, and malathion residue was not detected at any of the analyzed samples (Table 2). In comparison to locations the vegetables of Norsingdi, Jessore and Comilla received more insecticide residue then other locations. Some workers of India have found contamination with organophosphorus and pyrethroid pesticides in farm gate vegetables (Deka et al., 2005; Battu
Joia 2006). Chen et al. (2011) have revealed that the concentration of acephate and fenitrothion were in the range of not detected (nd) to 4.082 $\mathrm{mgkg}^{-1}$ and nd to $0.651 \mathrm{mgkg}^{-1}$, respectively in different vegetables from Xiamen city, China. El-Saeid and Selim (2013) detected residues of organophosphorus, organochlorine, pyrethroid and carbamate from market vegetables (viz., beans, egg plant, cauliflower, tomato, pepper, carrot, cucumber, squash, potato, onions and okra) which showed above the MRL in $15.89 \%$ of the total tested samples. Rahman et al. (2014) found $26 \%$ vegetables (viz., brinjal, hyachinth bean, cabbage, cauliflower and red amaranth) samples from five major vegetables growing regions (i.e., Bogra, Jessore, Norsingdi, Jamalpur and Rajshahi of Bangladesh) were contaminated with dimethoate, chlorpyriphos and quinalphos residues, of which $24 \%$ of the contaminated samples contained residue above MRL. The results of the present study were similar to the works of the above authors with little exception. However, contamination of single and multiple insecticide residues in vegetables over MRL is very harmful for human consumption. An effort should immediately be taken for quantification and documentation of insecticide residues in vegetables that helps decision maker, researchers and consumers to undertake activities for food safety. 


\section{Conclusions}

The results of the present study clearly indicated that vegetables those consumed daily indeed are contaminated by a number of insecticides. However, insecticide residue in vegetables over MRL can cause serious health hazard both wild life and human. So, continuous monitoring of pesticide residue would be needed in a large scale. Pesticide dealers/retailers and vegetables growers should be given training on the safe use and handling of pesticides in order to protect crops from pest infestation and reduce health hazards of end users.

\section{References}

Anonymous, 1979. Methods of sampling for the official control of pesticide residues in and on fruits and vegetables. July 24, European Commission Directive 79/700/EEC, Vol. 11, 75 p.

Anonymous. 1993. Codex alimentarius, pesticide residues in food. Joint $\mathrm{FAO} / \mathrm{WHO}$ Standards Program, FAO, Rome, Italy, Vol. 2, 378-386 pp.

Anonymous, 1996.Guidelines for the control of pesticide residues in foods. National Food Agency of Denmark (in Denish), 146 p.

Anonymous, 2001. Coordinated research on insecticide residue and resistance in major vegetables grown in Bangladesh. Report on Contact Research Project, BARC, BARI, Joydebpur, Gazipur, 102 p.

Ahmed, M. S., Sardar, M. A., Haque, M. A. And Kabir, K. H. 2005. A survey on the pattern of insecticidal usage for the protection of brinjal( Solanum melongena) from the attack of insect pests in Jessore. Bangladesh Journal of Zoology. 33(1): 57-63.

Battu, R. S. and Joia, B. S. 2006. Status of contamination of market samples of okra from Ludhiana, Punjab with pesticide residues. Journal of Insect Science, 19:185-189.

Berrada, H., Fernandez, M., Ruiz M. J., Molto J. C, Manes, J., Font, G. 2010.Surveillance of pesticide residues in fruits from Valencia during twenty months (200405). Food Control, 21: 36-44.

Chen, C., Qian, Y., Chen, Q., Tao, C., Li, C., Li, Y. 2011. Evaluation of pesticide residues in fruits and vegetables from Xiamen, China Food Control, 22: 1114-1120.

Deka, S. C., N. Barman and Baruah, A. L. H. 2005.Pesticidal contamination status in farm gate vegetables in Assam, India. Pesticide Research Journal, 17(2): 90-93.

El-Saeid, M. H. And Selim, M. T. 2013.Multiresidue analysis of 86 pesticides using Gas Chromatography Mass Spectrometry: II-non leafy vegetables. Journal of Chemistry, 2013, 110.http://dx.doi.org/10.1155/2013/727149

European commission, 2016.EU pesticides data base.http://ec.europa.eu/food/plant/pestici des/eu-pesticides-data base, (Accessed 27 October 2016).

FAO/WHO, 2016. Codex alimentarious, International food standards, http://www.fao.org/fao-whocodexalimentarius/standards/pestres/pestic ides/en.

Hossain, M. I., G. Shively and C. Mahmoud. 2000. Pesticide Expenditure in a Rice Vegetable Farming System: Evidence from Low-income Farms in Bangladesh, IPM-CRSP working paper 00-5.

Kabir, K. H., M. E. Baksh, F. M. A. Rouf, M. A. Karimand Ahmed, A. 1996. Insecticide usage pattern on vegetable at farmer level of Jessore region in Bangladesh: A Survey Finding. Bangladesh Journal of Agricultural Research, 20(2): 241-254.

Khatoon, J. A., M. S. Islam, N. M. Talukder and M. A. Hossain. 2004. Monitoring the 
residue level of three selected pesticides in Red Amaranth, Journal of Biological Science, 4(4): 474-479.

Rahman, M.A., Ahmed, M. S., Akon, M. W. and Afroza Begum, 2014. Pesticide residue analysis in vegetables collected from different regions of Bangladesh. In: Annual Report, 2013-2014.
Entomology Division, Bangladesh Agricultural Research Institute, Joybebpur, Gazipur, Bangladesh, 257263pp.

Rashid, M. A., S. N. Alam, F. M. A. Rouf and Taleker, N. S. 2003. Socio- economic parameters of eggplant pest control in Jessore district of Bangladesh. AVRDC Technical Bulletin, 29: 1-54. 